\title{
RELATO DE EXPERIÊNCIA E PRÁTICA DOCENTE TRABALHANDO A INTEGRAÇÃO EDUCACIONAL DE ALUNOS CEGOS
}

\author{
REPORT OF EXPERIENCE AND TEACHING PRACTICE WORKING ON THE \\ EDUCATIONAL INTEGRATION OF BLIND STUDENTS \\ RELATO DE EXPERIENCIA Y PRÁCTICA DOCENTE TRABAJANDO LA \\ INTEGRACIÓN EDUCATIVA DE ALUMNOS CIEGOS
}

\section{Victor Lucas Caldeira* \\ Hugo Silva Ferreira**}

*Docente da Secretaria Estadual de Educação de Minas Gerais. Licenciado em Sociologia pela Unopar. Cursa Pósgraduação lato sensu em Educação a Distância 4.0 na Sociedade Técnica Educacional da Lapa (FAEL) e em Ensino de Sociologia na Universidade Federal do Mato Grosso do Sul (UFMS) Faz Curso Técnico-profissionalizante em Tradução e Interpretação de Libras na Escola Estadual Francisco Sales pelo Instituto de Deficiência da Fala e Audição (IDFA). Contagem, Minas Gerais, Brasil. Orcid: https://orcid. org/0000-0001-9017-2647.

E-mail: victorlcaldeira1996@gmail.com

**Professor e pesquisador Associado do Programa de Estudos em Engenharia, Sociedade e Tecnologia do Centro Federal de Educação Tecnológica de Minas Gerais (Cefet$M G$ ). Pós-graduado em Docência do Ensino Superior e MBA em Gestão de Pessoas e Educação Corporativa na Faculdade do Vale Elvira Dayrell e Faculdade Educamais, respectivamente. Mestrando em Administração pela MUST University. Contagem, Minas Gerais, Brasil. Orcid: https://orcid. org/0000-0002-6511-9673.

E-mail: prof.hugosferreira@gmail.com

Recebido para publicação em: 28.3.2020

Aprovado em: 5.11.2020

\section{Resumo}

Este artigo desenvolve em seu escopo o relato de experiências vivenciadas na prática docente com estudantes cegos. Visa retratar os métodos didáticos interiorizados nesse cotidiano. A compilação de informações foi obtida de forma empírica, por meio de observações decorrentes do convívio, das descrições obtidas diretamente com os estudantes, além da pesquisa bibliográfica. A experiência evidencia o desafio que se constitui trabalhar nos moldes inclusivos, visto que a formação docente atual não antecipa exemplos de realidade, exigindo do educador uma postura dinâmica e proativa, capaz de educar no processo de integração humana do âmbito escolar.

Palavras-chave: Práticas docentes. Inclusão. Didáticas. Dinamismo. Deficiência visual.

\section{Abstract}

This article develops in its scope the report of experiences in teaching practice with blind students. It aims to portray the didactic methods internalized in this daily life. The compilation of information was obtained empirically, through observations arising from coexistence, descriptions obtained directly with the students, as well as bibliographic research. The experience highlights the challenge of working inclusively, since the current teacher training does not anticipate examples of reality, demanding from the educator a dynamic and proactive stance, capable of educating in the process of human integration in the school environment.

Keywords: Teaching practices. Inclusion. Didactic. Dynamism. Visual impairment. 


\section{Resumen}

Este artículo desarrolla, en su alcance, el relato de experiencias vividas en la práctica docente con estudiantes ciegos. Tiene como objetivo retratar los métodos didácticos interiorizados en esa vida cotidiana. La compilación de información se obtuvo de forma empírica, por medio de observaciones provenientes de la convivencia, descripciones obtenidas directamente con los estudiantes, además de investigación bibliográfica. La experiencia evidencia el desafío que constituye trabajar en las formas inclusivas, ya que la formación docente actual no anticipa ejemplos de realidad, exigiendo del educador una postura dinámica y proactiva, capaz de educar en el proceso de integración humana del ámbito escolar.

Palabras clave: Prácticas docentes. Inclusión. Didácticas. Dinamismo. Discapacidad visual.

\section{Introdução}

As pessoas com deficiência eram tratadas como beneficiários passivos de apoio, com sentimentos de piedade (LAMICHHANE; SAWADA, 2013). No Brasil, após a abordagem dos direitos das pessoas com deficiência, no Art. 201 da Constituição Federal de 1988, abriram-se caminhos para novas legislações dentro do tema. A Lei n. 7.853, de 1989, e o Decreto n. 3.298, de 20 de dezembro de 1999, caracterizaram um marco no mercado de trabalho. Por eles, normas e condutas para a acessibilidade constituíram uma nova forma de encarar a integração das pessoas com deficiência no Brasil (BRASIL, 1999).

A formação e capacitação docente é um dos fatores condicionantes

para a integração entre alunos do ensino regular e estudantes especiais

Nos dias atuais, o Brasil vive uma etapa de afloração dos movimentos sociais que demandam a implementação plena dos direitos conquistados, mas, em muitos casos, não respeitados (FRANÇA; PAGLIUCA; BAPTISTA, 2008). A exemplo destaca-se o direito à educação, da qual todos devem poder usufruir independentemente da sua condição clínica. Entretanto, em muitos casos não há um pleno usufruto desse direito devido aos fatores condicionantes para a sua plena execução. Assim, a formação e capacitação docente é um dos fatores condicionantes para a integração entre alunos do ensino regular e estudantes especiais.

De acordo com o documento Diretrizes Curriculares Nacionais da Educação Básica, entre as incumbências prescritas pela Lei de Diretrizes e Bases da Educação Nacional (LDB) aos estados e ao Distrito Federal está assegurar o Ensino Fundamental e oferecer, com prioridade, o Ensino Médio a todos que o demandarem (CONSELHO NACIONAL DE EDUCAÇÃO, 2013). Logo, é um direito de toda criança e adolescente ter acesso a educação, e deve existir como princípio docente a prioridade em sua formação para que haja a possibilidade de lidar com todo tipo de público, para receber positivamente todos os desafios que sua profissão demandar. 
No Censo Escolar da Educação Básica, realizado em 2010 pelo Instituto Nacional de Estudos e Pesquisas Educacionais Anísio Teixeira (Inep), órgão vinculado ao Ministério da Educação (MEC), 45.606.048 pessoas declararam possuir alguma deficiência, o que corresponde a $23,9 \%$ da população inventariada. Do total de pessoas, 82.525 fizeram matrículas na educação básica portando deficiência visual (classe especial e classe comum). Quatro anos depois, ao analisar os dados do Censo de 2014 (Gráfico 1), percebe-se redução considerável de matrículas, passando a somar um total de 76.481 alunos. A redução foi percebida tanto na classe especial quanto na classe comum.

\section{Gráfico 1 - Matrículas de estudantes com deficiência visual na Educação Básica}

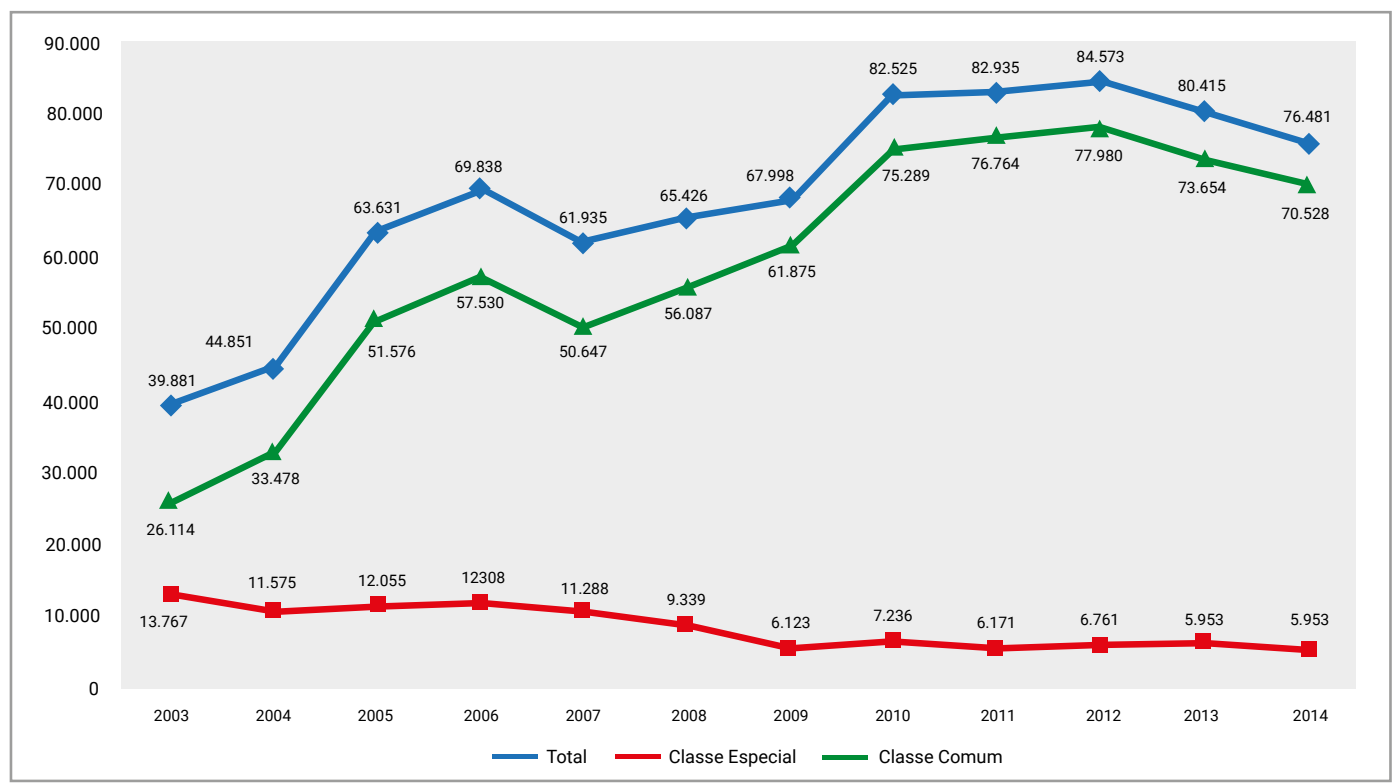

Fonte: Censo Escolar MEC/INEP (2014).

Em 2017, conforme informações do Observatório do Plano Nacional de Educação (OPNE), a porcentagem de matrículas de alunos com deficiência, transtornos globais do desenvolvimento e altas habilidades ou superdotação demonstrou crescimento nas classes comuns, chegando à marca de 84,12 pontos percentuais em comparação com o mesmo período em 2007, evidenciando um aumento de 37,3 pontos percentuais na demanda de vagas para estudantes especiais em escolas não especializadas para esse público diferenciado. Entretanto, as matrículas em escolas exclusivas diminuíram 27,8 pontos percentuais, totalizando $13,6 \%$ no censo escolar de 2017. No mesmo ano, matrículas em classes especiais apresentaram menor taxa, com 2,3\%. Conclui-se, pela análise dos dados, que é eminente o aumento dos alunos matriculados em classes comuns, do ensino regular básico, que possuem algum tipo de deficiência ou de superdotação. Esse crescimento 
precisa ser acompanhado pelos profissionais de educação por meio de educação continuada e formação complementar em educação especial. O preparo das estruturas arquitetônicas para receber os alunos especiais também é um fator para incluí-los.

Em contrapartida, o número de alunos com deficiência visual decresceu no ensino regular básico, o que levanta questões sobre o real preparo das instituições de ensino e dos profissionais de educação para receber esse público e promover a qualidade de ensino conforme suas necessidades especiais. No relato de experiência e prática docente que o presente artigo apresenta, percebe-se que os alunos com deficiência visual utilizam a escrita Braille para exercer as funções de escrita formal durante o ensino, linguagem não compreendida pelos profissionais de educação da instituição onde foi desenvolvida esta pesquisa.

Nem toda

formação

complementar

sobre educação

especial abarca

a completude

de necessidade

da prática

pedagógica

Em 2014, o número de docentes com formação na educação especial era de 97.459 profissionais, crescimento de 189\% desde o censo de 2003. É uma quantidade relativamente pequena, se comparada ao total de 886.815 alunos que são alvo da educação especial em escolas públicas da educação básica, como registrado pelo censo de 2014. Levantar questões sobre o estudo do tema para compreensão da queda de matrícula dos deficientes visuais no ensino regular básico é uma das funções deste relato. Portanto, considera-se importante diagnosticar e validar o real desenvolvimento dos educadores, pois nem toda formação complementar em educação especial abarca a completude de necessidade da prática pedagógica.

O MEC, em 2019, adotou medidas para tornar o acesso ao Exame Nacional do Ensino Médio (Enem) igualitário para todos os participantes, com ou sem deficiências. Essas medidas podem ser reproduzidas no dia a dia de ensino inclusivo, sendo soluções para a instituição de ensino e para o profissional docente como alternativa no acolhimento dos alunos deficientes. Entre as medidas observadas estão: provas em braile; tradutor-intérprete de Língua Brasileira de Sinais (Libras); provas com letras ampliadas e super-ampliadas; guia-intérprete para pessoas com surdo-cegueira; auxílios para leitura e transcrição; leitura labial; tempo adicional; sala de fácil acesso; e mobiliário acessível.

Como método, existe uma eficácia na proximidade e compreensão das estruturas sociais advindas de cada estudante, dessa forma cria-se a acessibilidade ao entendimento das necessidades, aos recursos que cada aluno dispõe, à compreensão das particularidades de sua deficiência. Assim haverá a facilidade de construção de um plano de trabalho para melhor produção e desempenho, pois "conhecer o desenvolvimento global do aluno, o diagnóstico, a avaliação funcional da visão, o contexto familiar e social, bem como as alternativas e os recursos disponíveis, facilitam o planejamento de atividades e a organização do trabalho pedagógico" (SÁ; CAMPOS; SILVA, 2007, p. 19). Levando em conta todos esses fatores, este artigo visa apresentar o relato de experiência docente em instituição de ensino com alunos deficientes visuais. 


\section{A experiência docente}

O respectivo relato utilizará o caso de dois estudantes distintos, um advindo do primeiro ano do ensino médio, que será denominado como A1, e o outro proveniente do terceiro ano do ensino médio, que será identificado como A2. Ressalta-se que nos dois casos há a especificidade da cegueira de forma única, sem o encargo de comprometimentos cognitivos. A vivência adquirida com os estudantes A1 e A2 advém do início do ano de 2020. A informação de que haveria estudantes com deficiências visuais em salas de aula provocou, por conta da escassez de vivência prática docente, desconforto e insegurança. A preocupação com a qualidade do ensino é um quesito que contribui para a insegurança do docente, mas também instiga um forte desejo de adaptabilidade para integração dos dois alunos no processo comum de aprendizagem.

Mesmo com pleno domínio da didática de ensino, a prática é um precioso objeto de complementação da formação docente. Sem ela, não se consegue experimentar todas as vivências do processo de ensino e aprendizagem, que foge da complexidade teórica do aprendizado de um licenciado docente. Segundo Nunes (2001), o professor, em sua trajetória profissional, depara-se com as práticas pedagógicas que o conduzem a formar conhecimentos conforme as necessidades de utilização no exercício da docência, e esses conhecimentos constituem as experiências e os percursos formativo e profissional desse tutor.

Nessa linha de raciocínio, destacam-se os fundamentos teóricos de Brzezinski e Garrido (2002) sobre em que medida os cursos de formação de professores correspondem às demandas propostas pela sociedade científica e tecnológica contemporânea, ou seja, se as competências desenvolvidas atualmente dentro do contexto teórico-prático estão formando verdadeiros profissionais. Por isso, advertem:

É necessário pôr em questão a formação pedagógica do licenciado, que, segundo algumas pesquisas já não responde às exigências do preparo para a docência, assim como é indispensável identificar as razões das constantes resistências de estagiários e professores para modificarem suas práticas pedagógicas (BRZEZINSKI; GARRIDO, 2002, p. 322).

Segundo Altet (2001), a formação acadêmica inicia os docentes em suas funções profissionais, já seu profissionalismo forma-se pelas suas experiências práticas.

A experiência vivida, o conhecimento íntimo das situações, a imersão no ofício, os estágios para observação do trabalho de colegas, as iniciativas pedagógicas testadas e as inovações, é que possibilitam aos professores o conhecimento do que é preciso fazer e de como fazê-lo. [...] 0 profissionalismo é constituído não só com a experiência e a prática em sala de aula, mas também com a ajuda de um mediador que facilita a tomada de consciência e de conhecimento (ALTET, 2001, p. 31-32).

Neste contexto, a experiência vivenciada, objeto desta pesquisa, destaca-se como material pedagógico instrutivo para outros profissionais, pois novos docentes pode- 
rão desenvolver o senso crítico formativo sob a luz dos proveitos da prática pedagógica do desafio no início de 2020. Ao se deparar com a necessidade de lecionar igualitariamente de forma integrada para alunos em situação atípica de aprendizagem, o primeiro passo para um bom preparo profissional foi a compreensão. Procurar entender as condições dos dois estudantes se fez crucial para desenvolver a postura profissional docente, assim como a didática e metodologia ativa de ensino, capaz de auxiliá-los qualitativamente no processo de aprendizagem.

Pode-se caracterizar a primeira etapa de preparação para a aula como prospecção de benchmarking para o processo de ensino, com a assimilação das boas práticas efetuadas por outros profissionais da educação que vivenciaram situação similar. Com base nos casos estudados, constatou-se, por exemplo, que ambos os alunos, A1 e A2, não apresentavam atrasos de desenvolvimento ou comprometimento das funções cognitivas, pelo contrário, o estudante A1, que tinha 16 anos, notoriamente esbanjava comprometimento, atenção e foco. Segundo dados coletados, ambos mostraram grande facilidade de integração no processo de comunicação e respostas aos comandos passados para a turma, ressaltando a ideia de Vigotsky (1997) de que uma pessoa que não utiliza a visão só é cega.

0 primeiro

passo para um

bom preparo

profissional foi

a compreensão

O aluno A1, para fazer os registros das matérias passadas em sala (conteúdo falado), utilizava uma máquina de escrever em braile, mas não conseguia reproduzir os conteúdos escritos na lousa, em materiais impressos ou em recursos didáticos tecnológicos, como slides. Fato que trouxe bastante desconforto ao corpo docente e administrativo da instituição, visto a unanimidade da ausência de compreensão da linguagem braile para envio dos conteúdos ao aluno A1. Já o aluno A2, 18 anos de idade, mostrou-se comunicativo, participando ativamente das aulas, com alto senso crítico nos debates dos conteúdos. Ele não copiava as matérias em aula (conteúdo escrito ou falado), mas utilizava softwares de aprendizagem e conversão de textos em sons. Com essa ferramenta, desempenhava um rigoroso estudo em casa, no dia anterior à aula, por meio da audição de todo o material. Nesse processo, o professor enviava todo o material da aula seguinte no e-mail do aluno A2, para que ele se preparasse, chegando em sala com todo o assunto e dúvidas memorizadas. Lembrando que para esse software o docente não precisava enviar o conteúdo em braile, pois o recurso tecnológico dominado por A2 já convertia textos escritos em textos orais.

A1 redigia em sala todo o conteúdo em braile, enquanto $A 2$ mantinha o processo de recebimento dos textos por e-mail e, por meio de softwares desenvolvidos para o público com deficiência visual, convertia-os para modelos sonoros, obtendo a possibilidade de registrá-los em braile e formatá-los em acesso auditivo. Mas, como A1 não possuía as habilidades nem os softwares para proceder no aprendizado como o aluno A2, ficava prejudicado por não ter acesso aos conteúdos escritos que os professores passavam em lousa. 
Uma intervenção docente, para criar uma metodologia de ensino eficaz e igualitária entre os alunos, tornou-se essencial. Para solução desse problema, foi proposto um sistema de rodízio entre os colegas de classe de A1, para que o aluno escalonado ficasse responsável por ditar todas as matérias escritas pelo professor, para que todo o conteúdo (escrito ou falado) fosse transposto para o braile. Sua eficácia foi logo percebida, fortalecendo a interação entre os alunos. Com o rodízio dos alunos auxiliares, criou-se um vínculo entres os estudantes, promovendo um sentimento de sustentação e coletividade. Outro ganho dessa metodologia implementada foi que, no decorrer do processo, constatou-se que os alunos auxiliares reforçaram seus próprios conhecimentos, por desempenharem a comunicação e releitura do conteúdo escrito na lousa. Ampliaram também a capacidade de produção de resumos e desenvolveram maior interação humana em sala de aula.

Nos últimos anos, no Brasil, o processo de inclusão de alunos com deficiência no sistema regular de ensino constitui-se em uma das mais acaloradas discussões, pela necessidade de amparo e fomento que a própria legislação impõe. No entanto, é evidente o despreparo do docente para receber, dentro da sala de aula regular, alunos com deficiência, tal como mostram os resultados das pesquisas dos estudiosos Naujorks (2002), Santos (2007), Smeha e Ferreira (2008) e Rodrigues (2008). Não basta impor e notar a necessidade de incluir alunos com deficiência na sala regular, se os educadores não possuem competências para promover qualitativamente o processo de ensino.

Segundo Smeha e Ferreira (2008), seguindo o conceito de competência para a educação, ao apresentar-se ainda como enigma para os educadores, transforma-se então em um fator de desestímulo profissional na área. As competências caracterizam saberes essenciais para a compreensão dos assuntos relacionados à formação e à prática do educador. Quando inseridas nas instituições de ensino, mostram-se um ponto de partida para a formação dos discentes com deficiências (AZAMBUJA; SOUZA; PAVÃO, 2012). Porém, mesmo com todas essas necessidades, é importante destacar que habilidades pessoais, adquiridas para cada particularidade de caso, são necessárias para lidar no dia a dia junto aos discentes com deficiência.

0 processo de inclusão de alunos com deficiência

no sistema regular de ensino constitui uma das mais acaloradas discussões
Após solução da primeira problemática, o corpo discente acusou que as correções do português dos estudantes não eram possíveis, sendo esse ponto um grande desfalque no processo de verificação da qualidade de escrita dos alunos, prejudicando os processos de alfabetização e sua formação como indivíduos. Ao focar o desenvolvimento de habilidades pessoais e profissionais intrínsecas no processo de ensino dos discentes $A 1$ e A2, o docente propôs um método de verificação do português de ambos os alunos. A1, o aluno que utiliza em sala de aula a escrita em braile, executaria a leitura de todo o material escrito por A2, redigido por meio de seu software de tradução e convertido em braile. Em contrapartida, A2 revisaria a escrita de A1, produzida diaria- 
mente dentro de sala de aula. No processo de intermediação, o docente poderia verificar o português de cada um e tornar o aprendizado mais satisfatório para ambos os discentes. Nessa situação há a necessidade de unir os dois alunos nessa prática. Por meio do método de observação crítica pelo docente da instituição de ensino, percebe-se que tal prática se tornou eficiente, sendo possível estendê-la para aplicação de provas.

No decorrer do $1^{\circ}$ bimestre de 2020, no surgimento de períodos livres, o regente de aulas ditou a prova de $\mathrm{A} 2$ para $\mathrm{A} 1$, transpondo-a para o braile, processo que demanda tempo e atenção. Já no caso de A2, a prova do A1 foi encaminhada via e-mail no decorrer do bimestre. Ele efetuou a entrega da prova transposta para o braile em data combinada, um procedimento eficiente, que não sobrecarregou nenhuma das partes envolvidas. Esse é um exemplo de adaptabilidade do docente para melhorar o processo de ensino pela integração entre alunos regulares e deficientes.

Como exposto por Pereira (2013), a aprendizagem na educação se integra ao aprender a aprender, a conviver e a ser, conhecimentos que garantem o desenvolvimento do profissional docente e o aperfeiçoamento das competências essenciais para desempenho da profissão. Para se implementar uma proposta de prática docente, foram adotadas metodologias de observação crítica, pesquisas bibliográfıcas e interação ativa com vivências educacionais de outros profissionais sobre o assunto. O processo de ensino mostrou-se eficaz em função da utilização de instrumentos pedagógicos capazes de desenvolver competências pessoais e habilidades humanas. Por meio do diálogo, construiu-se uma interação pedagógica capaz de criar canais de resolução de problemas e amplificação do engajamento com as ideias apresentadas. O feedback foi utilizado como ferramenta para indicar se o resultado final foi positivo ou negativo.

\section{Considerações finais}

Com base nas experiências práticas vivenciadas e nos estudos bibliográficos realizados neste trabalho, é clara a necessidade de implantação de um programa mais eficiente de capacitação de docentes, além da educação continuada, que atualmente é o recurso mais difundido para tal preparo. O processo de capacitação deve ser pautado não somente pelos estudos teóricos, mas pelas expertises práticas adquiridas, essenciais para o crescimento qualitativo das habilidades pessoais e humanas do profissional educador.

As questões levantadas neste relato levam à compreensão de que a educação especial é factível de ser alcançada e integrada à educação regular pelos avanços dinâmicos da didática de ensino e dispor metodológico do profissional docente, aliados aos avanços de saberes médicos, psicológicos e pedagógicos. Aqui destaca-se a expertise do saber pedagógico docente, ferramenta circunstancial para que o processo de ensino aos alunos A1 e A2 fosse positivo. Seria possível avan- 
çar mais no tema de estudo e apresentar as dificuldades impostas durante todo o ano letivo do ano de 2020. Contudo, este não é o principal intuito deste relato, visto que a complexidade vivenciada por diversas situações com os dois alunos cegos levanta questões de grande abrangência para os pesquisadores. Assim, busca-se, a partir do exposto neste artigo, que mais pesquisas venham a dinamizar essas questões: como está o processo de avaliação e diagnóstico da formação docente? A formação docente atual se fortifica em pilares de capacitação e desenvolvimento pessoal e humano? Na formação acadêmica dos profissionais de educação está apresentada capacitação profissional para situações de inclusão pedagógica?

Vale destacar que as soluções adotadas neste relato foram medidas pedagógicas aplicadas conforme as necessidades levantadas e os recursos disponíveis. É evidente que uma capacitação docente para leitura em braile ou até recursos tecnológicos para adaptabilidade dos materiais didáticos a esse público é um caminho mais eficaz para o processo de inclusão educacional dos alunos deficientes. Contudo, além de protagonistas do saber, os docentes aqui responsáveis assumem uma postura de cobrança das autoridades para adequar o ambiente escolar e torná-lo mais inclusivo. Portanto, refletindo sobre este estudo, evidenciam-se as problemáticas do tema, pois, por elas, aponta-se um modo de atuação do profissional educador, determinando por si as dimensões da qualidade de ensino capaz de validar o processo pedagógico.

\section{Referências}

ALTET, Marguerite. As competências do professor profissional: entre conhecimentos, esquemas de ação e adaptação, saber analisar. In: ALTET, Marguerite; CHARLIER, Eveline; PAQUAY, Léopold; PERRENOUD, Philippe.

Formando professores profissionais: quais estratégias? Quais competências? Porto Alegre: ARTMED, 2001. p. 31-32.

AZAMBUJA, Guacira de; SOUZA, Carmen Rosane Segatto e; PAVÃO, Sílvia Maria de Oliveira. Cultura de educação inclusiva: a educação especial e os processos formativos de professores. Revista Reflexão e Ação, Santa Cruz do Sul, v. 20, n. 2, p. 291-308, jun./dez. 2012. DOI 10.17058/rea.v20i2.2770. Disponível em: https:// online.unisc.br/seer/index.php/reflex/article/view/2770/2249.

Acesso em: 12 mar. 2020.

BRASIL. Ministério da Educação. Pessoas com deficiência. Brasília, DF: MEC, [1999]. Disponível em: http://portal.mec.gov.br/component/tags/tag/32105pessoas-com-deficiencia. Acesso em: 27 mar. 2020.

BRASIL. Ministério da Educação. Principais indicadores da educação de pessoas 
com deficiência: Censo MEC/INEP. Brasília, DF: MEC, [2014?]. Disponível em: http:// portal.mec.gov.br/index.php?option=com_docman\&view=download\&alias=17655secadi-principais-indicadores-da-educacao-especial\&category_slug=junho-2015pdf\&ltemid=30192. Acesso em: 12 mar. 2020.

BRZEZINSKI, Iria; GARRIDO, Elza. O que revelam os trabalhos apresentados no GT Formação de Professores da ANPED. Série Estado do Conhecimento, Brasília, DF, v. 1, n. 6, p. 303-328, 2002. Tema: Formação de Professores no Brasil (1990-1998).

CONSELHO NACIONAL DE EDUCAÇÃO (Brasil). Câmara Nacional de Educação Básica. Diretrizes curriculares nacionais da educação básica. Brasília, DF: MEC, 2013. Disponível em: http://portal.mec.gov.br/index.php?option=com_ docman\&view=download\&alias=15548-d-c-n-educacao-basica-novapdf\&ltemid=30192. Acesso em: 12 de mar. 2020.

FRANCA, Inacia Sátiro Xavier de; PAGLIUCA, Lorita Marlena Freitag; BAPTISTA, Rosilene Santos. Política de inclusão do portador de deficiência: possibilidades e limites. Acta Paulista de Enfermagem, São Paulo, v. 21, n. 1, p. 112-116, jan./ mar. 2008. DOI 10.1590/S0103-21002008000100018. Disponível em: https://www. scielo.br/pdf/ape/v21n1/pt_17.pdf. Acesso em: 12 mar. 2020.

LAMICHHANE, Kamal; SAWADA, Yasuyuki. Disability and returns to education in a developing country. Economics of Education Review, [s. I.], v. 37, p. 85-94, 2013. DOI. 10.1016/j.econedurev.2013.08.007. Disponível em: https://www.sciencedirect. com/science/article/abs/pii/S027277571300109X. Acesso em: 12 mar. 2020.

NAUJORKS, Maria Inês. Stress e inclusão: indicadores de stress em professores frente à inclusão de alunos com necessidades educacionais especiais.

Revista Educação Especial, Santa Maria, RS, n. 20, p. 117-25, 2002. DOI 10.5902/1984686X. Disponível em: https://periodicos.ufsm.br/educacaoespecial/ article/view/5125/3105. Acesso em: 12 mar. 2020.

NUNES, Célia Maria Fernandes. Saberes docentes e formação de professores: um breve panorama da pesquisa brasileira. Educação \& Sociedade, Campinas, ano 22, n. 74, p. 27-42, abr. 2001. Disponível em: https://www.scielo.br/pdf/es/v22n74/ a03v2274.pdf. Acesso em: 12 mar. 2020.

PEREIRA, Fabiana Kremem. Pedagogia das competências na educação profissional: contribuições da formação continuada para saberes e competência docente.

E-Tech: Tecnologias para Competitividade Industrial, n. 3. esp. Educação, p. 31-52, 2013. DOI 10.18624/e-tech.v0i0.393. Disponível em: http://etech.sc.senai.br/index. php/edicao01/article/view/393/334. Acesso em: 12 mar. 2020. 
RODRIGUES, David. Desenvolver a educação inclusiva: dimensões do desenvolvimento profissional. Inclusão - Revista da Educação Especial, Brasília, DF, v. 4, n. 2, p. 7-16, jul./out. 2008.

SÁ, Elizabet Dias de; CAMPOS, Izilda Maria de; SILVA, Myriam Beatriz Campolina. Atendimento educacional especializado: deficiência visual. Brasília, DF: SEESP/ SEED/MEC, 2007.

SANTOS, Mônica Pereira dos. Relatório de pesquisa: ressignificando a formação de professores para uma educação inclusiva. Rio de Janeiro: UFRJ/LaPEADE, 2007.

SMEHA, Luciane Najar; FERREIRA, lolete de Vilieger. Prazer e sofrimento docente nos processos de inclusão escolar. Revista Educação Especial, Santa Maria, RS, v. 1, n. 31, p. 37-48, 2008. DOI 10.5902/1984686X. Disponível em: https://periodicos. ufsm.br/educacaoespecial/article/view/8/20. Acesso em: 12 mar. 2020.

VIGOTSKY, Lev. Obras escogidas V: fundamentos de defectologia. Madrid: Visor, 1997. 